\title{
Cholinesterase inhibitor treatment alters the natural history of Alzheimer's disease
}

\author{
O L Lopez, J T Becker, S Wisniewski, J Saxton, D I Kaufer, S T DeKosky
}

J Neurol Neurosurg Psychiatry 2002;72:310-314

See end of article for authors' affiliations

.....................

Correspondence to: Dr O L Lopez Neuropsychology Research Program, 3501 Forbes

Avenue, Suite 830

Pittsburgh, PA 15213, USA

Received 21 May 2001

In revised form

17 October 2001

Accepted

25 October 2001
(CEls) on the natural course of Alzheimer's Objective: To describe the effect of cholinesterase inhibitors (CEIs) on the natural course of Alzheimer's
disease (AD).

Methods: The short and long term effects of CEls were evaluated in 135 patients with probable Alzheimer's disease relative to 135 patients who were never exposed to CEls matched by age, education, duration of the symptoms, and cognitive status. We measured 1 year change in cognitive and functional performance, and the likelihood of arriving at each of four end points: (1) mini mental state examination (MMSE) of 9 or lower, (2) Blessed dementia rating scale for activities of daily living of 12 or higher, (3) nursing home admission, and (4) death, over an average 3 years of observation (36.7 (SD 21.5 ) months).

Results: Patients on CEls were better cognitively and functionally after 1 year compared with those patients who never used CEls. A proportional hazard analysis with CEI use as a time dependent covariate showed that the use of CEls decreased the risk of nursing home admission. There was no association, however, between use of CEls and time to cognitive and functional end points, or to death.

Conclusions: This observational study showed that there was an initial cognitive and functional benefit from the use of CEls in Alzheimer's disease, which waned as the disease progressed. However, the results suggest that there is a long term beneficial effect of the use of CEls, as indicated by the delay in adsmission to nursing homes.
C holinomimetic drugs constitute the first line of treatment for Alzheimer's disease (AD), and cholinesterase inhibitors (CEIs) were the first medication approved by the US Food and Drug Administration for the treatment of cognitive deficits in Alzheimer's disease. ${ }^{1-4}$ The CEIs have proved effective in slowing down apparent clinical progression in 12,24 , and 30 week placebo controlled trials, ${ }^{13-8}$ and some studies have shown that there is no loss of benefit after 1 year of treatment.9-12 Moreover, extention studies of placebo controlled trials have shown that the effects of CEIs may last more than 1 year. ${ }^{13}{ }^{14}$ However, although little is known about the longer term effects of CEIs, there are a few studies that have suggested that they can alter the natural course of Alzheimer's disease. For example, patients receiving high doses of tacrine ( $>80 \mathrm{mg}$ /day) during a 30 week randomised, double blind, placebo controlled study, were less likely to have entered a nursing home after 2 years than those receiving low doses. $^{15}$

Most of the present efficacy data on CEIs are derived from placebo controlled trials. However, as the use of these compounds becomes more common, especially by primary care physicians, understanding the efficacy of these drugs over a longer period becomes increasingly important. The purpose of the present study is to describe the effects of CEIs on the natural history of the disease in a non-selected cohort followed up for an average of 3 years. We report here the short and long term effects of open label CEI use on the traditional milestones of Alzheimer's disease (time to severe cognitive and functional decline, entry into a nursing home, and death) in a large group of patients with probable Alzheimer's disease.

\section{MATERIAL AND METHODS}

The patients of this study were selected from a cohort of $1094^{16}$ patients with probable Alzheimer's disease who were recruited into the Alzheimer's Disease Research Centre at the University of Pittsburgh between April 1983 and June 1999.
Two hundred and four patients (19\%) in the centre took CEIs at some point during their follow up, and from this group, we selected only those $(n=135)$ who had at least one follow up evaluation 9 -14 months after they began taking CEIs (mean 12.44 (SD 2.0) months), and who continued taking the CEIs until the last contact with our clinic. Patients who were exposed to medication for a short period were not entered in this study. One hundred and thirty of the treated patients took donepezil, 22 tacrine, and six rivastigmine. Twenty two of these patients took part in CEI drug trials (donepezil, rivastigmine). Except for three patients who died before 1997, all patients taking tacrine were switched to donepezil when this medication became available. Two of the six patients that participated in the rivastigmine trial had a marked benefit from this drug, and continued on compassionate use. The other four patients continued on donepezil when the study was completed.

The data from these treated patients were compared and contrasted with those of 135 patients from the same cohort who were never exposed to CEIs. These patients were matched on a 1:1 basis to a treated patient for age, education level, duration of symptoms, mini mental state examination (MMSE) score, ${ }^{17}$ and date of study entry ( \pm 3 years).

Each participant in this observational study received an extensive neuropsychiatric evaluation including medical history and physical examination, neurological history and examination, semistructured psychiatric interview, and neuropsychological assessment, and the results were reviewed

Abbreviations: $C E l s$, cholinesterase inhibitors; MMSE, mini mental state examination; HDRS, Hamilton depression rating scale; DSM-IV, statistical manual of mental disorders, fourth edition; EPS, extrapyramidal signs; BDRS, Blessed dementia rating scale; MDRS, Mattis dementia rating scale; CDR, clinical dementia rating; HRS, Hachinski rating scale; 
Table 1 Inclusion and exclusion criteria

$\begin{array}{ll}\text { Inclusion criteria: } \\ 1 & \text { Progressive cognitive deficits } \\ 2 & \text { Age }>40 \\ 3 & \text { Native English speaker } \\ 4 & \text { Adequate visual and auditory acuity to complete neuropsychological testing } \\ 5 & \text { Reliable caregiver who is capable of providing correct information about the patients } \\ \text { Exclusion criteria: } & \\ 1 & \text { Lifetime history of schizophrenia, manic depressive disorder, or schizoaffective disorder } \\ 2 & \text { History of electroconvulsive therapy } \\ 3 & \text { Current alcohol or drug misuse/dependence, or history of alcohol or drug misuse/dependence } \\ 4 & \text { within } 2 \text { years of the onset of the symptoms of dementia } \\ 5 & \text { Subjects with history of cancer within the previous } 5 \text { years } \\ & \text { Current significant disease or unstable medical condition that could affect neuropsychological } \\ & \text { testing (chronic renal failure, chronic hepatic disease, severe pulmonary disease) }\end{array}$

at a consensus diagnostic conference. ${ }^{18}{ }^{19}$ The inclusion and exclusion criteria are shown in table 1.

\section{Dementia criteria}

The diagnosis of dementia was based on a progressive cognitive deterioration, in the absence of reversible causes of cognitive impairment, and history of normal intellectual function before the onset of cognitive abnormalities. Patients were required to have impairments in two cognitive domains, which did not necessarily include memory ${ }^{16}$ The sensitivity for Alzheimer's disease is $98 \%$, and specificity $88 \%$ at the Alzheimer's Disease Research Centre of Pittsburgh. ${ }^{18} 19$

\section{Psychiatric evaluation}

Psychiatric evaluations were conducted by geriatric psychiatrists using a semistructured interview with the patient and their primary care giver(s). ${ }^{20}$ The Consortium for the Establishment of a Register for Alzheimer's Disease Behavioural Scale, ${ }^{21}$ and the Hamilton depression rating scale (HDRS $)^{22}$ were also completed by the psychiatrists on the basis of data from each patient and primary care giver. The diagnosis of major depression was made according to the diagnostic and statistical manual of mental disorders, fourth edition (DSM-IV) criteria. ${ }^{23}$ Delusions were defined in accordance with the DSM-IV and were distinguished from confabulations, disorientation, and amnesia by requiring the endorsement that false beliefs persisted despite evidence of the contrary. Details of the clinical criteria for the diagnosis of depression, delusions, and hallucinations have been described previously. ${ }^{24}$

\section{Neurological evaluation}

The neurological examination was performed by both a neurologist and a physician's assistant trained in the medical examination of demented patients and elderly people. ${ }^{25}$ The extrapyramidal signs (EPS) were rated using individual items of the New York University scale for parkinsonism, ${ }^{26}$ which includes: (1) resting and postural tremors; (2) rigidity of neck, arms, or legs on passive movements of major joints; (3) bradykinesia; (4) postural instability, (5) abnormal gait; and (6) dyskinesia (for example, limbs, face, tongue). A patient was considered to have EPS when at least one of the signs listed above was recorded.

\section{Outcome measures}

\section{Functional assessment}

Functional capacity was assessed with the Blessed dementia rating scale (BDRS) for activities of daily living. ${ }^{27}$ We used a BDRS score of 12 or more as the end point, which represents a moderate to severe functional impairment.

\section{Global cognitive function}

Global cognitive function was assessed using the MMSE, ${ }^{17}$ and an MMSE score of less than 9 was used as the end point because it represents moderate-severe dementia.

\section{Institutionalisation}

We considered nursing home admission to have occurred when the patient was admitted to a nursing home regardless of the level of care (for instance, personal care facility, healthcare facility).

Table 2 Demographic and neuropsychiatric measures

\begin{tabular}{lllll}
\hline & $\begin{array}{l}\text { Patients } \\
\text { on CEls }\end{array}$ & $\begin{array}{l}\text { Patients who } \\
\text { never used CEls }\end{array}$ & $\chi^{2} / t$ test & p Value \\
\hline $\begin{array}{l}\text { Number of patients: } \\
\text { Overall follow up (months) }\end{array}$ & 135 & 135 & & \\
(range) & $34.6(21.3)$ & $39.0(21.1)$ & 1.93 & 0.05 \\
Male/female & $(9-101)$ & $(9-97)$ & & \\
Education (y) & $46 / 95$ & $51 / 90$ & 0.39 & 0.61 \\
Age & $12.8(3.1)$ & $12.3(3.2)$ & 1.60 & 0.10 \\
Duration of symptoms (y) & $72.7(7.2)$ & $72.8(8.4)$ & 0.28 & 0.92 \\
MMSE & $4.5(2.6)$ & $4.1(2.4)$ & -1.56 & 0.11 \\
MDRS & $18.7(7.2)$ & $18.8(7.3)$ & 0.13 & 0.89 \\
CDR & $115.0(16.9)$ & $110.3(18.9)$ & -2.17 & 0.04 \\
BDRS for ADLs & $1.25(0.54)$ & $1.25(0.53)$ & -0.08 & 0.95 \\
HDRS & $4.9(3.2)$ & $5.9(3.2)$ & 2.22 & 0.02 \\
HRS & $6.0(4.1)$ & $6.4(1.9)$ & 0.90 & 0.36 \\
NYU scale & $2.5(1.9)$ & $2.5(2.1)$ & -0.30 & 0.76 \\
\hline
\end{tabular}

Values in parentheses are SD unless otherwise stated.

MMSE, mini mental state examination; MDRS, Mattis dementia rating scale; $C D R$, clinical dementia rating; BDRS for ADLs, Blessed dementia rating scale for activities of daily living; HRS, Hachinski rating scale; HDRS Hamilton depression rating scale; NYU, New York University scale for parkinsonism. 
Table 3 Medical, neurological, and psychiatric characteristics

\begin{tabular}{|c|c|c|c|c|}
\hline & $\begin{array}{l}\text { Patients } \\
\text { on CEls } \\
(\%)\end{array}$ & $\begin{array}{l}\text { Patients who } \\
\text { never used CEls } \\
\text { (\%) }\end{array}$ & $\chi^{2}$ & $\mathrm{p}$ Value \\
\hline \multicolumn{5}{|l|}{ Extrapyramidal signs: } \\
\hline Baseline: & $74(55)$ & $90(67)$ & 3.49 & 0.06 \\
\hline Follow up & $101(75)$ & $105(78)$ & 0.32 & 0.56 \\
\hline \multicolumn{5}{|l|}{ Psychosis: } \\
\hline Baseline & $53(39)$ & $59(44)$ & 0.54 & 0.53 \\
\hline Follow up & $68(50)$ & $72(53)$ & 0.23 & 0.62 \\
\hline \multicolumn{5}{|l|}{ Major depression: } \\
\hline Baseline & $19(14)$ & $14(10)$ & 0.86 & 0.35 \\
\hline Follow up & 17 (13) & $11(8)$ & 1.43 & 0.23 \\
\hline \multicolumn{5}{|l|}{ Medication use: } \\
\hline \multicolumn{5}{|l|}{ Sedatives } \\
\hline Baseline & $14(10)$ & $8(6)$ & 1.72 & 0.18 \\
\hline Follow up & $12(9)$ & $17(13)$ & 0.96 & 0.32 \\
\hline \multicolumn{5}{|l|}{ Antidepressants } \\
\hline Baseline & $39(29)$ & $35(26)$ & 0.29 & 0.58 \\
\hline Follow up & $41(30)$ & $35(26)$ & 0.65 & 0.41 \\
\hline \multicolumn{5}{|l|}{ Antipsychotics } \\
\hline Baseline & $4(3)$ & $14(10)$ & 5.95 & 0.02 \\
\hline Follow up & $10(7)$ & $32(26)$ & 13.6 & $<0.001$ \\
\hline Hypertension & $45(33)$ & $49(36)$ & 0.26 & 0.60 \\
\hline Diabetes mellitus & $3(2)$ & $7(5)$ & 0.66 & 0.69 \\
\hline Ischaemic heart disease & $9(7)$ & $12(9)$ & 0.46 & 0.49 \\
\hline Pulmonary disease & $4(3)$ & $4(3)$ & 0.00 & 1.00 \\
\hline Stroke at follow up & $8(6)$ & $11(8)$ & 0.51 & 0.47 \\
\hline
\end{tabular}

\section{Statistical analysis}

Cox proportional hazard models were used to determine the relation between CEI use and the outcome measures, while adjusting for possible confounding variables such as education, age, baseline MMSE (dichotomised as $\leqslant 19$ or $>19$ ), and BDRS (dichotomised as $\leqslant 6$ or $>6$ ) scores, and sex. Because many patients were given CEIs during follow up, the overall effect of CEIs on the outcomes was assessed as a time dependent covariate. These indicator variables were included in the stepwise selection procedures. Once a model was selected, the proportionality of the hazards was assessed using a time dependent variable for each factor in the model. No significant deviations from proportionality were noted. For those patients not reaching an outcome (for example, death) the data were censored using the date of the last contact.

\section{RESULTS}

The baseline demographic and clinical characteristics of the patients are described in table 2. Patients who never used CEIs were followed up for a slightly longer period, and had a worse Mattis dementia rating scale (MDRS) ${ }^{28}$ and BDRS for activities of daily living scores than those taking these drugs. The proportion of men and women was similar between groups, and there was no statistical differences for MMSE, clinical dementia rating (CDR), ${ }^{29}$ Hachinski rating scale (HRS), ${ }^{30}$ HDRS, and the New York University scale scores.

Table 3 shows the medical, neurological, and psychiatric characteristics of the patients. There were no differences between groups in the rate of extrapyramidal signs, psychosis, major depression, hypertension, diabetes mellitus, ischaemic heart disease, pulmonary disease (for example, chronic obstructive pulmonary disease), and strokes. However, patients who never used CEIs were more likely to take antipsychotic medication at baseline and at follow up examinations.

\section{Baseline versus 1 year follow up}

The scores on the MMSE and BDRS scales were analyzed with a two factor (drug and time) analysis of covariance (ANCOVA) in the 270 patients, using age and education as covariates. For the MMSE there was a significant effect of time $(F(1,266)=0.69 .3, \quad \mathrm{p}<0.0001)$, but not of drug use
$(F(1,266)=0.906, \mathrm{p}=0.34)$. There was a significant difference in the rate of change in the MMSE between the CEI users and untreated patients $(F(1,266)=4.49, \mathrm{p}=0.03)$ (MMSE scores at follow up: CEIs users $=16.3($ SD 6.2) $v$ never used CEIs $=14.8$ (SD 6.3)).

The BDRS was administered to all patients at baseline. However, due to a temporary change in the study protocol, 1 year follow up data were available on 84 patients in the nondrug group, and 125 in those taking CEIs. The within patient ANCOVA found that for the patients with both baseline and 1 year follow up scores, there was also no significant effect of time $(F(1,205)=1.93, \mathrm{p}=0.16)$, but the CEIs users had significantly lower scores than the untreated patients overall $(F(1,205)=7.83, \mathrm{p}=0.003)$ (BDRS scores at follow up: CEI users $=4.7($ SD 3.3) $v$ never used CEIs $=7.3($ SD 4.3)). More important, however, was the fact that there was a significant difference in the rate of change in the BDRS between the users of CEIs and untreated patients $(F(1,205)=14.6, \mathrm{p}<0.001)$.

\section{Survival analysis}

There was a greater proportion of patients who never used CEIs reaching the four end points than those who used CEIs (table 4). The adjusted Cox proportional hazard model, which controlled for the effects of age, education, duration of symptoms, and baseline BDRS and MMSE scores, showed that CEI use was significantly associated only with a reduction in the risk of entry into a nursing home $(\mathrm{RR}=033,95 \%$ CI $0.57-0.70$, $\mathrm{p}=0.004)$; no association was found between CEI use and time

Table 4 Number of patients and outcomes

\begin{tabular}{lllll}
\hline & $\begin{array}{l}\text { Patients } \\
\text { on CEls } \\
(\%)\end{array}$ & $\begin{array}{l}\text { Patients } \\
\text { who never } \\
\text { used CEls } \\
(\%)\end{array}$ & $\chi^{2}$ & p Value \\
\hline Death & $17(13)$ & $52(38.5)$ & 23.8 & $<0.0001$ \\
BDRS $>12$ & $35(26)$ & $62(46)$ & 13.1 & $<0.0001$ \\
MMSE <9 & $38(28)$ & $67(49)$ & 11.7 & 0.001 \\
Institutionalisation: & $8(6)$ & $56(41.5)$ & 47.1 & $<0.0001$ \\
\hline
\end{tabular}




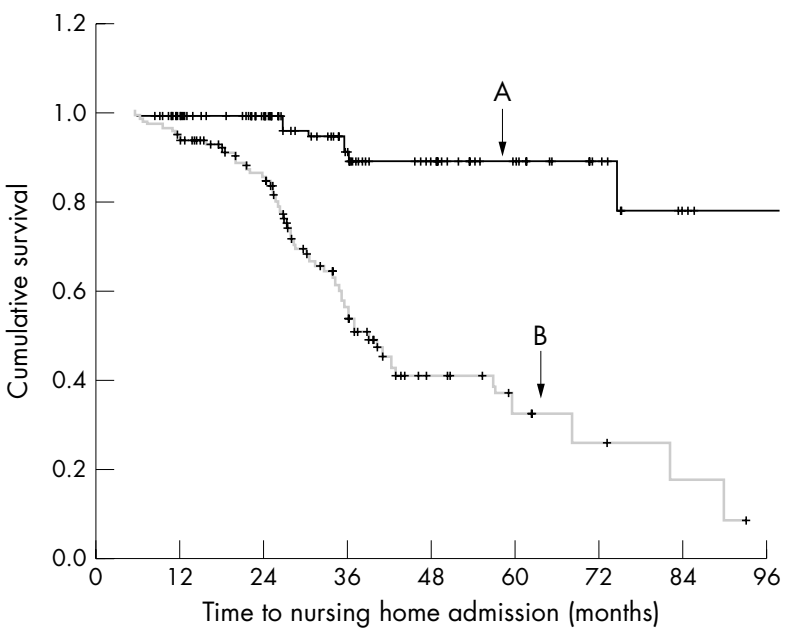

Figure 1 Kaplan-Meier plot of time to nursing home admission among patients with Alzheimer's disease $(A)$ taking and $(B)$ not taking CEls.

to death $(\mathrm{RR}=0.38,95 \% \mathrm{CI} 0.14-1.04, \mathrm{p}=0.07)$, time to MMSE $\leqslant 9(\mathrm{RR}=0.76,95 \%$ CI $0.45-1.27, \mathrm{p}=0.30)$, or time to BDRS $\geqslant 12(\mathrm{RR}=0.75,95 \%$ CI $0.43-1.32, \mathrm{p}=0.32)($ fig 1$)$.

\section{DISCUSSION}

This is the first study that has used traditionally recognised end points to assess the effects of CEIs on the natural history of Alzheimer's disease outside the context of double blind, placebo controlled clinical trials and open label trials (or open label continuation studies). Our results show that there was an initial cognitive and functional benefit from the use of CEIs, which waned as the disease progressed. Based on our own data and those of others ${ }^{31}$ we would expect an annual 3-4 point decline in the MMSE scores in untreated patients. However, among the treated patients the mean decline was significantly smaller ( 2.5 points). More importantly, there was a long term benefit of CEI use by delaying admission to a nursing home. Among the untreated patients, more than $40 \%$ were admitted to nursing homes during the 3 year follow up interval, versus only $6 \%$ of the treated patients.

The treatment of Alzheimer's disease must necessarily focus on the fact that it is a gradually progressive neurodegenerative disorder, and the efficacy of its treatment is best measured over long time periods - that is, alterations in the natural history of the disorder. Whereas short term benefits in cognitive and functional competence with CEI use are to be expected, ${ }^{9-12}$ it is the longer term outcome (the delay of entry into a nursing home) that demonstrates the powerful effect of these drugs. ${ }^{15}$ This suggests that physicians must be cautious in judging the medication response after only a few months of treatment, as the full benefits of CEI use take place over a longer time frame. Indeed, even reports of "change" by the family should be viewed as treatment success.

Our results are consistent with those of Knopman et al, who found that patients with Alzheimer's disease who used tacrine at more than $80 \mathrm{mg} /$ day, and remained on the medication for about 2 years, had lower risk of nursing home admission than those who either discontinued the treatment or continued on lower doses. ${ }^{15}$ In addition, that study also reported a trend towards decreased mortality. However, these were patients who were participating in a clinical trial, and who were relatively healthier than those who did not meet entry criteria, which may have accounted for the findings. In our study, by contrast, there was no such selection bias between groups, and consequently, the rates of systemic illness were similar in patients taking CEI and those not taking medication. Furthermore, the presence of EPS ${ }^{25}$ and psychiatric disorders (for example, psychosis), ${ }^{32}$ both of which are known to affect progression in Alzheimer's disease, did not differ between groups. Therefore, the differences in the rate of response cannot be attributed to these factors.

The fact that the use of CEIs delays time to nursing home admission and does not affect physical survival has important scientific and public health implications. The CEIs seem to allow the patients to maintain relatively normal activities of daily living for a longer period of time, but do so without significantly prolonging life. Given the significant delay in entry to a nursing home, we would have predicted an increase in functional (BDRS) or cognitive (MMSE) survival, as well. However, the fact that we did not see a protective effect on functional or cognitive outcome, suggests that these scales, at least, did not capture properly the aspects of the syndrome that affected the decision to admit to a nursing home. Further studies with more complete neuropsychological and functional assessment may disclose what specific cognitive or other function(s) have been affected by CEIs.

Observational studies are different from placebo controlled studies in that the placebo controlled studies were designed to test the efficacy and safety of CEIs in a group of patients with few comorbidities (for example, major depression, psychiatric medication use, uncontrolled cardiovascular disease), and over a short period (for example, 12-30 weeks); often, this was followed by an open labelled period to determine the long term effects of CEIs. However, none of these studies took into account events that may have occurred during the the open label phase, such us development of psychiatric symptoms, use of psychiatric medication, strokes, or neurological symptomatology. Moreover, these studies have been shown to have a high attrition rate. For example, only 45 of the 398 patients examined in the open labelled, multicentre, study of donepezil completed the 144 weeks of follow up,,$^{13}$ and 111 of 431 completed the 1 year placebo controlled study of preservation of function survival of donepezil. ${ }^{12}$

By contrast, observational studies focus on the factors that can modify the natural history of the disease. Therefore, they can provide a more "real world" perspective of the long term effects of the CEIs, and represent reasonable second tier evidence of drug efficacy. They can also take into account events that can affect the study outcomes; in this study, patients who were never exposed to CEIs used more antipsychotic drugs, at baseline and at follow up, than those who used CEIs. The use of antipsychotic drugs has been associated with increased risk of functional and cognitive decline and admission to a nursing home, ${ }^{32}{ }^{33}$ and the use of sedative/hypnotic drugs with death. ${ }^{32}$ However, after controlling for the use of these drugs, the results of the survival analysis remained unchanged.

The patients that were not treated with CEIs in this study were different from those enrolled in the placebo arm of placebo controlled studies. Our patients never intended to use medication, at least until their last clinic contact or death. Some patients were afraid of the side effects (for example, hepatotoxicity, nausea, vomiting), especially with tacrine, a fear that persisted even after the introduction of the new CEIs with fewer side effects. In addition, because of the lack of information about long term efficacy of CEIs, many care givers as well as family physicians had a nihilistic view of the palliative treatment of Alzheimer's disease, and did not favour their use. This attitude, seen in the 1990s, towards Alzheimer's disease medication has been gradually disappearing, and now most of the patients with Alzheimer's disease seen in referral clinics are taking CEIs. Indeed, as noted here, and in recent studies of long term efficacy of CEIs, the use of these medications can alter the natural history of the disease. Therefore, the availability of a historical cohort gave us the opportunity to compare the long term benefits of CEIs between two a distinct groups of patients. Studies such as this will be very difficult to perform in the future when most of the patients will be taking at least one medication for Alzheimer's disease. 
An understanding of the natural history of a neurodegenerative process has important medical and social implications. Researchers have focused their attention on how predispositional factors affect progression of Alzheimer's disease (for example, cognitive and functional decline, time to institutionalisation, and death); age at symptom onset, education, and sex can all affect progression, especially the time to death, or admission to a nursing home. The present study shows that the introduction of medication to treat Alzheimer's disease can alter important outcomes in the natural course of the disease. Further research is needed to identify those patients who do not respond to CEIs, why they do not respond, and how best to treat this subgroup of Alzheimer's disease.

\section{ADDENDUM}

Although the BDRS was routinely completed at study entry, due to manpower limitations it was sometimes omitted at 1 year follow up. This was not based on patient characteristics, and thus, the missing data are considered random. The data presented in table 2 and in the text are from all patients providing data. The results of the ANCOVA shown here are taken only from the patients with two BDRS scores, 1 year apart. From both sets of data it is clear that the BDRS scores of the untreated patients rose (more impaired), whereas those of the treated patients, at worse, did not change over 12 months. The Cox proportional hazard model was developed using the data of 270 patients, since they all had the opportunity to provide more than one BDRS score.

\section{ACKNOWLEDGEMENTS}

This study was supported by grants AG03705 and AG05133 from the National Institute on Aging. JTB. is a recipient of the Research Scientist Development Award (level II) (K02-MH01077).

\section{Authors' affiliations}

O L Lopez, J T Becker, S Wisniewski, J Saxton, D I Kaufer

S T DeKosky, Alzheimer's Disease Research Center, University of Pittsburgh School of Medicine, Pittsburgh, PA, USA

O L Lopez, J T Becker, J Saxton, D I Kaufer, S T DeKosky,

Department of Psychiatry

O L Lopez, J T Becker, D I Kaufer, S T DeKosky, Department of

Neurology

S Wisniewski, Department of Epidemiology

\section{REFERENCES}

1 Farlow M, Gracon SI, Hershey LA, et al. A controlled trial of tacrine in Alzheimer's disease. The Tacrine Study Group. JAMA 1992;268:2523-9.

2 Rogers SL, Friedhoff LT. The efficacy and safety of donepezil in patients with Alzheimer's disease: results of a US multicentre, randomized, double-blind, placebo-controlled trual. The Donepezil Study Group. Dementia 1996; 7:293-303.

3 Rosler M, Anand R, Cicin-Sain A, et al. Efficacy and safety of rivastigmine in patients with Alzheimer's disease: international randomised controlled trial. BM 1999;318:633-8.

4 Tariot PN, Solomon PR, Morris JC, et al. A 5 month, randomized, placebo-controlled trial of galantamine in AD. Neurology 2000;54:2269-76

5 Rogers SL, Doody RS, Mohs RC, et al. Donepezil improves cognition and global function in Alzheimer disease. Arch Intern Med 1998; 158:1021-31.

6 Thal LJ, Ferguson JM, Mintzer J, et al. A 24 week randomized trial of controlled-release physostigmine in patients with Alzheimer's disease. Neurology 1999:52:1146-52.

7 Rogers SL, Farlow MR, Doody RS, et al. A 24 week, double-blind, placebo-controlled trial of donepezil in patients with Alzheimer's disease. Donepezil Study Group. Neurology 1998;50:136-45.
8 Qizibash N, Whitehead A, Higgins J, et al. Cholinesterase inhibition for Alzheimer's disease: a meta-analysis of the tacrine trials. JAMA 1998;280: 1777-82.

9 Rogers SL, Friedhoff LT. Long-term efficacy and safety of donepezil in the treatment of Alzheimer's disease: an interim analysis of the results of a US multicentre open label extension study. Eur Neuropsychopharmacol 1998;8:67-75.

10 Winblad B, Engedal K, Soininen HS, et al. A 1 year, randomized, placebo-controlled study of donepezil in patients with mild to moderate AD. Neurology 2001;57:489-95.

11 Raskind MA, Peskind ER, Wessel T, et al. Galantamine in AD. A 6 month, randomized, placebo-controlled trial with a 6 month extension. Neurology 2000;54:2261-8.

12 Mohs RC, Doody RS, Morris JC, et al. A 1-year, placebo-controlled preservation of function survival study of donepezil in $A D$ patients. Neurology 2001;57:481-8.

13 Doody RS, Geldmacher DS, Gordon B, et al. Open-label, multicenter, phase 3 extension study of the safety and efficacy of donepezil in patients with Alzheimer's disease. Arch Neurol 2001;58:427-33.

14 Rogers SL, Doody RS, Pratt RD, et al. Long-term efficacy and safety of donepezil in the treatment of Alzheimer's disease: final analysis of a US multicenter open-label study. Eur Neuropsychopharmacol 2000;10:195-203

15 Knopman D, Schneider L, Davis K, et al. Long-term tacrine (Cognex) treatment: effects on nursing home placement and mortality. Neurology 1996;47: 166-77.

16 McKhann G, Drachman DA, Folstein MF, et al. Clinical diagnosis of Alzheimer's disease: report of the NINCDS-ADRDA Work Group under the auspices of the Department of Health and Human Services Task Force on Alzheimer's disease. Neurology 1984;34:939-44.

17 Folstein MF, Folstein SE, McHugh PR. Mini-mental state: a practical method grading the cognitive state of patients for the clinician. Psychiatry Res 1975;12:189-98.

18 Lopez OL, Becker JT, Klunk W, et al. Research evaluation and diagnosis of possible Alzheimer's disease over the last 2 decades: I. Neurology 2000;55: 1854-62.

19 Lopez OL, Becker JT, Klunk W, et al. Research evaluation and diagnosis of possible Alzheimer's disease over the last 2 decades: II. Neurology 2000;55:1863-9.

20 Mezzich JE, Dow JT, Cottman GA. Developing an information system for a comprehensive psychiatric institute, I. Principles, design, and organization. Behaviour Research Methods and Instrumentation 1981;13:459-63

21 Tariot PN, Mack JL, Patterson MB, et al. The behavior rating scale for dementia of the Consortium to Establish a Registry for Alzheimer's Disease. Am J Psychiatry 1995:152:1349-57.

22 Hamilton $M$. A rating scale for depression. J Neurol Neurosurg Psychiatry 1960;23:56-62.

23 American Psychiatric Association. Diagnostic and statistic manual of mental disorders, 4th ed (DSM-IV). Washington, DC: American Psychiatric Association, 1994.

24 Lopez OL, Gonzalez MP, Becker JT, et al. Symptoms of depression and psychosis in Alzheimer's disease and frontotemporal dementia. Neuropsychiatry Neuropsychol Behav Neurol 1996:9:154-61.

25 Lopez OL, Wisnieski SR, Becker JT, et al. Extrapyramidal signs in patients with probable Alzheimer's disease. Arch Neurol 1997;54:969-75

26 Hoehm M, Yahr M. Parkinsonism: onset, progression, and mortality. Neurology 1967;17:427-42.

27 Blessed G, Tomlinson BE, Roth $M$. The association between quantitative measures of dementia and senile changes in the cerebral white matter of elderly subjects. Br J Psychiatry 1968;1 14:797-811.

28 Mattis $\mathrm{S}$. Mental status examination for organic mental syndrome in the elderly patient. In: Bellak L, Karuso TB, eds. Geriatric psychiatry. New York: Grune and Stratton, 1976

29 Hughes CP, Berg L, Danzinger WL. A new clinical scale for the staging of dementia. Br J Psychiatry 1982;140:566-72.

30 Hachinski VC, lliff LD, Zihka $E$, et al. Cerebral blood flow in dementia. Arch Neurol 1975;32:632-7.

31 Salmon DP, Thal LJ, Butters N, et al. Longitudinal evaluation of dementia of the Alzheimer type: a comparison of three standardized mental status examinations. Neurology 1990:40:1225-30.

32 Lopez OL, Wisniewski SR, Becker JT, et al. Psychiatric medication and abnormal behavior as predictors of progression in probable Alzheimer's disease. Arch Neurol 1999;56:1266-72.

33 McShane R, Keene J, Gedling K, et al. Do neuroleptic drugs hasten cognitive decline in dementia: prospective study with necropsy follow up. BN 1997;314:266-70. 